\title{
openheart Psychosocial and clinical outcomes of percutaneous versus surgical pulmonary valve implantation
}

\author{
Brith Andresen, ${ }^{1,2,3}$ Gaute Døhlen, ${ }^{4}$ Lien My Diep, ${ }^{5}$ Harald Lindberg, ${ }^{2,3}$ Erik Fosse, ${ }^{1,3}$ \\ Marit Helen Andersen $6,7,8$
}

To cite: Andresen B, Døhlen G, Diep LM, et al. Psychosocial and clinical outcomes of percutaneous versus surgical pulmonary valve implantation. Open Heart 2018;5:e000758. doi:10.1136/

openhrt-2017-000758

Received 6 December 2017 Revised 21 February 2018 Accepted 6 March 2018

\section{Check for updates}

${ }^{1}$ Intervention Centre, 0slo University Hospital, Oslo, Norway 2Department of Cardiothoracic Surgery, Oslo University Hospital, Oslo, Norway ${ }^{3}$ Institute of Clinical Medicine, Faculty of Medicine, University of Oslo, Oslo, Norway ${ }^{4}$ Department of Pediatric Cardiology, Oslo University Hospital, Oslo, Norway ${ }^{5}$ Oslo Centre for Biostatistics and Epidemiology, Oslo University Hospital, Oslo, Norway ${ }^{6}$ Department of Transplantation Medicine, Oslo University Hospital, Oslo, Norway ${ }^{7}$ Department of Transplant Medicine, Oslo University Hospital, Oslo, Norway

${ }^{8}$ Institute of Health and Society, Faculty of Medicine, University of Oslo, Oslo, Norway

Correspondence to Dr Brith Andresen; brandres@ ous-hf.no

\section{ABSTRACT}

Objective This prospective non-randomised study was performed to compare the psychosocial function and clinical outcomes following surgical and percutaneous implantation of a pulmonary valve at 3 months and 1 year after treatment.

Methods All patients were consecutively admitted for treatment by either method from June 2011 to October 2014. The data of 20 patients treated with the percutaneous technique and 14 patients treated with open heart surgery were compared. Psychosocial function was measured by the Achenbach System of Empirically Based Assessment (ASEBA). We used linear mixed-effect models to investigate group changes between the psychosocial function and clinical data of 34 patients with congenital pulmonary valve disease.

Results A significant difference in favour of the percutaneous pulmonary valve implantation group was observed regarding the ASEBA scores, specifically in the Thought problems subscale at 1 year $(p=0.015)$, Attention problems subscale at 3 months $(p=0.016)$ and 1 year $(p=0.007)$ after treatment. After adjustment for the right ventricle to pulmonary artery pressure gradient at 3 months, a significant change in the Attention problems subscale $(p=0.038)$ was noted in the percutaneous group. The New York Heart Association functional score significantly improved in both groups. The measured right ventricle to pulmonary artery pressure gradient was reduced significantly in both groups at 1 year.

Conclusions Both methods led to significant clinical improvement. Thought and attention problems such as intrusive behaviour significantly decreased only in patients who underwent the percutaneous procedure. Complications as reintervention, bleeding and arrhythmia were only observed in the open surgery group.

\section{INTRODUCTION}

Percutaneous pulmonary valve implantation (PPVI) for selected patients with right ventricle outflow tract (RVOT) obstruction or insufficiency was introduced in 2000 as a complementary technique to surgical pulmonary valve replacement. ${ }^{1-6}$ Device-related and technique-related improvements ${ }^{7}$ have resulted in expanded performance of PPVI with increasingly more patient groups being accepted for treatment. ${ }^{8}$ Long-term follow-up

\section{Key questions}

What is already known about this subject?

- Both treatment techniques are associated with good clinical outcomes. An easy rehabilitation and rapid life normalisation are described as positive experiences in the percutaneous pulmonary valve implantation group. However, the psychosocial outcome between the two treatment groups after treatment remains unknown.

What does this study add?

- In the percutaneous pulmonary valve group, a sig nificant improvement was observed in subscales within psychosocial function. No significant improvements were observed in the open surgery group.

How might this impact on clinical practice?

- Subscales within psychosocial function was in favour of the percutaneous pulmonary valve implantation group 3 months and 1 year after treatment However, future studies involving a larger sample population and longer-term follow-up are warranted to confirm our results.

results have indicated improved and sustained haemodynamics after the procedure. ${ }^{1} 910$ Patients have reported positive impacts on psychosocial function and normalisation of life after treatment. ${ }^{11} 12$ Surgical valve replacement is a successful procedure with low mortality. However, repeated sternotomy is a predictor of prolonged hospitalisation and may increase the risk of complications. ${ }^{13}$ Inattention, hyperactivity and poor school performance are described in children with complex heart disease. ${ }^{14-16}$ Possible causes include underlying neurobehavioural impairment, genetic and epigenetic factors, surgical and interventional procedures, cerebral microembolisation, cerebral hypoperfusion, anaesthesia exposure, an inflammatory response, or simply psychological and physical strain caused by repeated surgeries. ${ }^{14}$ 16-18 A strategy for prevention 
and lifelong perspective is important in modern healthcare, hence to alleviate neurodevelopmental and neurovascular risk factors is crucial. ${ }^{16} 19$ The possible impact of PPVI on patients' psychosocial function should not be underestimated. When evaluating new treatments, patient-reported outcomes are important in estimating the psychosocial results of therapy. ${ }^{20}$ Knowledge is limited regarding the relationship between patient-reported outcomes addressing psychosocial function and clinical data in patients who have undergone PPVI or open heart surgery. We aimed to compare the short-term and intermediate-term clinical and psychosocial outcomes after percutaneous and surgical techniques.

A priori, we hypothesised that (1) a significant improvement in clinical and psychosocial outcomes would occur in both treatment groups and (2) a difference in patient-reported outcomes would be noted between the two groups at 3 months and would be in favour of the PPVI group.

\section{METHODS \\ Design}

A single-centre, prospective case-control study.

\section{Setting}

All Norwegian patients eligible for surgical or interventional treatment for RVOT dysfunction are centralised to one centre at Oslo University Hospital. Recruitment was performed by sending an information letter to patients and/or their closest relatives before they arrived at the hospital. Informed consent was given by the patient for patients $>18$ years of age and by the parents/closest relatives for younger patients. A team of four thoracic surgeons and one interventional cardiologist working in close collaboration performed all RVOT procedures. A procedural strategy reflecting international guidelines ${ }^{21}$ was planned for both paediatric and adult patients, using the same criteria for both procedures.

\section{Patients}

Thirty-four consecutive patients were included in the study in the period of June 2011 to October 2014 (20 in the PPVI group and 14 in the open surgery group); 23 of these patients were children (15 in the PPVI group and 8 in the open surgery group). The inclusion was not randomised because the percutaneous technique could not be applied in all patients due to mechanical restrictions.

The inclusion criteria were independent of procedure technique, based on international principles of treatment within the field ${ }^{22}$ and a consensus set by the local treatment team. The exclusion criteria were aggressive endocarditis, conduit of $>22 \mathrm{~mm}$ and no circumferential foreign material. All included patients had information on their former surgery (conduit type and size), clinical indication and gradient of their stenosis (as measured by echocardiography, cardiac MRI or catheterisation). All patients in both groups required pulmonary valve replacement secondary to a failed surgical procedure to repair the RVOT.

\section{Interventions}

Percutaneous intervention group

Pre-stenting performed up to 3 months before the procedure was considered part of the PPVI procedure. The vascular access route for the percutaneous pulmonary valve was either transfemoral or transjugular. Cardiac catheterisation with assessment of the right heart and pulmonary and aortic pressures preceded each implantation. According to the standard procedure, all patients underwent angiographic coronary visualisation during pulmonary artery balloon inflation to evaluate the potential risk of coronary compression by implantation of the percutaneous valve.

\section{Open surgery group}

The surgical valves were implanted after a midline sternotomy, either directly under a patch or in a Gore-Tex conduit. After preparation of the necessary mediastinal structures, bicaval and ascending aortic cannulation was performed. Cardiopulmonary bypass was initiated, and the patient was cooled to a temperature of $32^{\circ} \mathrm{C}$. The aorta was then cross-clamped, and St. Thomas crystalline cardioplegia was delivered. Appropriate exposure and preparation of the RVOT was performed, and a valve was implanted in the pulmonary position using a standard technique. When necessary, a Gore-Tex patch was placed for enlargement of the RVOT. After rewarming and reperfusion, the patient was weaned from cardiopulmonary bypass and the wound was closed in a standard fashion.

\section{Treatment}

Anaesthesia and monitoring were standardised for both treatment groups. Induction was performed with benzodiazepines and maintained with gas and fentanyl. All patients in the PPVI group were extubated before leaving the angiographic suite. The patients in the open surgery group were transferred to the intensive care unit after surgery ${ }^{23}$ and extubated when their haemodynamics and respiratory status were stable. Chest tubes were routinely removed on postoperative day 1 .

\section{Analgesia}

Analgesics were administered according to established protocols. At the start of the operation, a single dose of fentanyl was administered intravenously, whereas paracetamol and ketorolac were administered at the end of anaesthesia. In the open surgery group, at the start of the postoperative phase on day 0 , paracetamol was administered according to a fixed protocol with ketorolac/ morphine intravenously as needed. From postoperative day 1, the patients received oral paracetamol. Ketorolac and additional analgesia were thereafter administered as needed. 


\section{Study outcomes}

Patient-reported outcomes (psychosocial function) were assessed using the Achenbach System of Empirically Based Assessment (ASEBA) and New York Heart Association (NYHA) functional class. The clinical outcomes were mortality, reintervention or reoperation, complications such a stent fracture and arrhythmia, the right ventricle to pulmonary artery pressure gradient and the degree of pulmonary regurgitation measured before and after treatment.

\section{Patient-reported outcomes}

Psychosocial function

The ASEBA ${ }^{24}$ was used to assess psychosocial function before treatment and twice postoperatively in both groups. This is a generic, comprehensive, self-administered outcome measure of social functioning. It comprises 112 items that are used to measure symptoms in eight subscales: Anxiety/Depression, Withdrawal, Social complaints, Thought problems, Attention problems, Intrusive behaviour, Aggressive behaviour and Delinquent behaviour. Items are scored on a 3-point scale, and lower scores indicate poorer functioning. ${ }^{24} 25$ The Youth Self-Report questionnaire targets patients aged 11 to 18 years, while the Adult Self-Report questionnaire targets patients aged 18 to 59 years; each questionnaire was used as appropriate. The questionnaire was administered to all patients aged $>11$ years. The timing of data collection was based on the time intervals that were expected to maximise the treatment benefit and intermediate results. All patients were instructed to complete the questionnaire according to their perceived status of well-being at that time.

Changes in the NYHA classification of heart failure were measured through a self-reported questionnaire collected before treatment and twice postoperatively (3 months and 1 year). ${ }^{26}$

\section{Clinical outcomes}

The following data were collected before treatment and twice postoperatively ( 3 months and 1 year) in both groups: change in the measured right ventricle to pulmonary artery pressure gradient and the degree of pulmonary regurgitation. The right ventricle to pulmonary artery gradient pressure was measured in millimetres of mercury, while the pulmonary regurgitation was graded in five levels (0-4) defined as none, trace, mild, severe and free. ${ }^{21}$

\section{Statistical analysis}

Differences between two independent proportions were tested by Fisher's exact test or the $\chi^{2}$ test and differences between two independent samples means were tested by the Mann-Whitney U test. Within-group changes from the preoperative period to 3 months and 1 year postoperatively were examined by the Wilcoxon signed-rank test for pulmonary stenosis, pulmonary regurgitation and NYHA classification. Otherwise, a mixed-effect linear regression model was used to fit multiple data points per patient, whereas the outcome variable was the psychosocial function score, the NYHA classification, cardiac function and length of stay. In the mixed model, patient identification was a random variable while time and group with interaction timexgroup were treated as fixed variables. The crude and adjusted mean changes from baseline to 3 months and 1 year, SD and $\mathrm{p}$ values were calculated for each group. The $\mathrm{p}$ values were not adjusted for multiple outcomes, and significance was set at $\mathrm{p}<0.05$.

Statistical analyses were performed with IBM Statistical Package for the Social Sciences (SPSS).

\section{RESULTS \\ Patient characteristics}

The two groups were comparable with regard to baseline characteristics: gender, age, body weight and number of previous open heart surgeries. However, the groups differed significantly with respect to valvular disease: stenosis was the main disorder in the PPVI group, while pulmonary regurgitation or combined disease were the main disorders in the open surgery group. Among the 20 patients in the PPVI group, 16 received a Medtronic Melody valve (Medtronic, Minneapolis, Minnesota, USA) and 4 received an Edwards SAPIEN valve (Edwards Lifesciences, Irvine, California, USA). ${ }^{23}$ Two of the patients underwent pre-stenting 1 and 3 months prior to valve implantation, while nine patients underwent pre-stenting during the implantation procedure. A median of 1 (range, 1-3) pre-stent was used. Of the 14 patients in the open surgery group, 11 received a Carpentier-Edwards Perimount Magna valve (Edwards Lifesciences), 2 received a Contegra bovine jugular valved conduit (Medtronic) and 1 received a pulmonary homograft (table 1 ).

\section{Clinical endpoints}

In the PPVI group, no procedure was cancelled because of unfavourable coronary localisation. High-pressure pre-dilatation of the pulmonary valve was performed in 13 patients $(65 \%)$, and high-pressure post-dilatation was performed in 8 patients $(40 \%)$.

Baseline clinical data showed a statistical difference between groups. Concerning pulmonary stenosis, there was a statistical finding showing more patients in the PPVI group diagnosed with pulmonary stenosis and a mixed lesion compared with the open surgery group.

The measured right ventricle to pulmonary artery pressure gradient was reduced significantly in the percutaneous pulmonary valve group from baseline 67 (10-96) $\mathrm{mm} \mathrm{Hg}$ to $19(11-30)$ at 3 months $(\mathrm{p}<0.001)$, and at 1 year $19(9-56)(\mathrm{p}<0.001)$ after treatment. In the surgery group, the change in measured right ventricle to pulmonary artery pressure gradient was not significant at 3 months, but at 1 year after treatment, the gradient was reduced to $20(7-36)(p=0.010)$. In the percutaneous group, NYHA class function was reduced from baseline $2(1-4)$ to $1(1-2)$ after 3 months $(p=0.021)$. After 1 year, 
Table 1 Patient characteristics and baseline data

\begin{tabular}{|c|c|c|c|}
\hline & $\begin{array}{l}\text { Percutaneous pulmonary } \\
\text { valve replacement }(n=20)\end{array}$ & $\begin{array}{l}\text { Open heart surgery } \\
\text { pulmonary valve replacement } \\
(n=14)\end{array}$ & P values \\
\hline Female sex & $7(35.0)$ & $5(35.7)$ & 1.00 \\
\hline Age (years) & $14(8-36)$ & $23(9-53)$ & 0.323 \\
\hline Weight (kg) & $43.0(26-85)$ & $63.0(25-92)$ & 0.274 \\
\hline No of previous open heart surgeries & $2.5(1-4)$ & $2.0(1-4)$ & 0.416 \\
\hline \multicolumn{4}{|l|}{ Diagnosis } \\
\hline Tetralogy of Fallot, all variants & $8(40)$ & $11(79)$ & 0.038 \\
\hline Pulmonary atresia, VSD & $5(25)$ & $2(14)$ & 0.378 \\
\hline Truncus arteriosus communis & $3(15)$ & $1(7)$ & 0.627 \\
\hline TGA, PS, VSD & $4(20)$ & $0(0)$ & 0.126 \\
\hline \multicolumn{4}{|l|}{ RV-to-PA pressure/lesion } \\
\hline Predominant PS ${ }^{1}$ & $15(75)$ & $2(14)$ & 0.001 \\
\hline Predominant $\mathrm{PR}^{2}$ & $4(20)$ & $6(43)$ & 0.252 \\
\hline Mixed lesion ${ }^{3}$ & $1(5)$ & $6(43)$ & 0.012 \\
\hline \multicolumn{4}{|l|}{ RVOT } \\
\hline Native or patch-extended RVOT & $4(20)$ & $4(28)$ & 0.689 \\
\hline Homograft RV-to-PA conduit & $4(20)$ & $2(14)$ & 1.000 \\
\hline Contegra RV-to-PA conduit & $1(5)$ & $1(7)$ & 1.000 \\
\hline Bioprosthesis (eg, Hancock, Carpentier-Edwards) & $10(50)$ & $1(7)$ & 0.011 \\
\hline Other (GoreTex valve re-construction) & $1(5)$ & $6(43)$ & 0.012 \\
\hline
\end{tabular}

Data are presented as $\mathrm{n}(\%)$ or median (range).

${ }^{1} \mathrm{PS}$, pre-echo peak RVOT velocity/gradient $\geq 50 \mathrm{~mm} \mathrm{Hg}$.

${ }^{2} \mathrm{PR}$, pre-echo peak RVOT velocity/gradient $<50 \mathrm{~mm} \mathrm{Hg}$.

${ }^{3}$ Mixed lesion, mild stenosis and more than moderate insufficiency.

Bold numbers are statistical significant values.

PA, pulmonary artery; PS, pulmonary stenosis; RV, right ventricle; RVOT, right ventricular outflow tract; TGA, transposition of the great arteries; VSD, ventricular septal defect.

the functional NYHA class was still significant 1 (1-3) ( $p$ value $=0.034$ ).

In the surgery group, NYHA class function was significantly reduced from baseline 2 (1-3) to 3 months 1 (1-2) $(\mathrm{p}=0.004)$, and the improvement was not significant at 1 year.

Pulmonary regurgitation level was reduced significantly in the percutaneous group from baseline $3(0-4)$ to 3 months $0(0-2) \quad(\mathrm{p}<0.001)$, at 1 year the improvement sustained significant at $0(0-2)(\mathrm{p}=0.003)$. In the surgery group, the pulmonary regurgitation level was reduced significantly from baseline $4(0-4)$ to 3 months $1(0-2)$. One year after treatment, the level sustained significant at $1(0-2) \quad(\mathrm{p}=0.003) \quad$ (table 2$)$.

No acute adverse events occurred in the PPVI group. One patient in the open surgery group underwent a reoperation and needed blood transfusion because of bleeding. Another patient required pacemaker implantation after surgery because of a permanent heart block. One patient in this group developed ventricular tachycardia before surgery and therefore received an implantable cardioverter defibrillator after surgery (table 3 ).

\section{Psychosocial function}

Baseline data were comparable between the groups. In the PPVI group, a significant improvement was observed in the Thought problems subscale from baseline to 1 year postoperatively $(\mathrm{p}=0.015)$, the Attention problems subscale at 3 months $(\mathrm{p}=0.016)$ and 1 year $(\mathrm{p}=0.007)$ after treatment. No significant improvements were observed in the open surgery group. No significant differences in psychosocial function before and after treatment were observed between the two groups.

Psychosocial function was assessed only in patients aged $>11$ years; this contributed to missing data in this study because the response rate for the ASEBA scores was only $63 \%$ (table 4 ).

\section{Association between clinical and psychosocial outcomes}

In the PPVI group, a significant association was found between the right ventricle to pulmonary artery gradient pressure and psychosocial function with respect to the Anxiety/Depression subscale at 3 months postoperatively (4.19) $(\mathrm{p}=0.038)$. This association was not significant in the same treatment group at 1 year postoperatively (3.66) 
Table 2 Changes in clinical outcomes within groups from baseline to 3 months and 1 year after treatment

\begin{tabular}{|c|c|c|c|c|c|c|}
\hline & $\begin{array}{l}\text { Percutaneous } \\
\text { pulmonary valve } \\
\text { replacement }(n=20)\end{array}$ & $\begin{array}{l}\text { Missing } \\
\text { numbers }\end{array}$ & P values* & $\begin{array}{l}\text { Open heart surgery } \\
\text { pulmonary valve } \\
\text { replacement }(n=14)\end{array}$ & $\begin{array}{l}\text { Missing } \\
\text { numbers }\end{array}$ & P values* \\
\hline \multicolumn{7}{|l|}{ Pulmonary stenosis (mm Hg) } \\
\hline Baseline & $67(10-96)$ & 0 & & $40(12-112)$ & 0 & \\
\hline 3 months postoperatively & $19(11-30)$ & 0 & $<0.001$ & $14(5-36)$ & 5 & 0.123 \\
\hline 12 months postoperatively & $19(9-56)$ & 1 & $<0.001$ & $20(7-36)$ & 0 & 0.010 \\
\hline \multicolumn{7}{|c|}{ Pulmonary regurgitation (levels $0-4)^{\star \star}$} \\
\hline Baseline & $3(0-4)$ & 0 & & $4(0-4)$ & 0 & \\
\hline 3 months postoperatively & $0(0-2)$ & 0 & 0.007 & $1(0-2)$ & 3 & 0.001 \\
\hline 12 months postoperatively & $0(0-2)$ & 1 & 0.003 & $1(0-2)$ & 0 & 0.003 \\
\hline \multicolumn{7}{|l|}{ NYHA classification (levels 1-4) } \\
\hline Preoperatively & $2(1-4)$ & 0 & & $2(1-3)$ & 0 & \\
\hline 3 months postoperatively & $1(1-2)$ & 3 & 0.021 & $1(1-2)$ & 1 & 0.004 \\
\hline 12 months postoperatively & $1(1-3)$ & 11 & 0.034 & $1(1-3)$ & 7 & 0.102 \\
\hline
\end{tabular}

Data are presented as median (range).

*Wilcoxon signed-rank test. The $p$ values were not adjusted for multiple testing.

**Levels 0-4: 0, none; 1, trace; 2, mild; 3, severe; and 4, free.

NYHA, New York Heart Association.

Bold numbers are statistical significant values.

$(\mathrm{p}=0.058)$. No significant association of psychosocial function with the length of stay, pulmonary regurgitation or NYHA classification of heart failure was found between the two groups.

\section{DISCUSSION}

In both groups, a significant improvement in clinical endpoints was found at 3 months; however, only in the percutaneous group improvements sustained significant

Table 3 Procedural and clinical variables

$\begin{array}{ll}\begin{array}{l}\text { Percutaneous pulmonary } \\ \text { valve replacement }\end{array} & \begin{array}{l}\text { Open heart surgery } \\ \text { pulmonary valve } \\ (n=20)\end{array} \\ \text { replacement }(n=14)\end{array}$

$P$ values

\begin{tabular}{|c|c|c|c|}
\hline \multicolumn{4}{|l|}{ Preoperative and postoperative variables } \\
\hline \multicolumn{4}{|l|}{ Vascular access route } \\
\hline Transfemoral & $16(80)$ & & \\
\hline Transjugular & $4(12)$ & & \\
\hline Procedural time (h) & $3.05 \pm 0.69$ & $2.79 \pm 0.70$ & \\
\hline Postoperative respirator time (min) & $0(0-0)$ & $240(65-1005)$ & \\
\hline Length of stay (h) & $58 \pm 27$ & $243 \pm 78$ & $<0.001$ \\
\hline Postoperative bleeding $(\mathrm{mL})^{1}$ & $0(0-0)$ & $650(285-3840)$ & \\
\hline Postoperative transfusion $(\mathrm{mL})^{2}$ & $0(0-0)$ & $550(0-7690)$ & \\
\hline Stent fractures within 1 year postoperatively & 0 & & \\
\hline Endocarditis within 1 year postoperatively & 0 & 0 & \\
\hline Pacemaker within the same hospital stay & 0 & 1 & \\
\hline ICD within the same hospital stay & 0 & 1 & \\
\hline Reinterventions & 0 & 1 & \\
\hline
\end{tabular}

Data are presented as $\mathrm{n}, \mathrm{n}(\%)$, mean \pm SD or median (range).

${ }^{1}$ Day 1 postoperatively.

${ }^{2}$ Transfusions given day 1 postoperatively: erythrocyte concentrate (SAG), fresh frozen plasma (Octaplas), thrombocytes, blood from the heart and lung machine.

ICD, implantable cardioverter defibrillator.

Bold numbers are statistical significant values. 
Table 4 Change in psychosocial function in both treatment groups within the different subscales from baseline to 1 year after treatment

\begin{tabular}{|c|c|c|c|c|c|c|}
\hline $\begin{array}{l}\text { Psychosocial function } \\
\text { subscales } 1-8\end{array}$ & $\begin{array}{l}\text { Percutaneous } \\
\text { pulmonary valve } \\
\text { replacement } \\
n=15^{\star \star} \\
n=1 \text { (baseline) } \\
n=2 \text { (3 months) } \\
n=5 \text { (1 year) }\end{array}$ & Change & P values* & $\begin{array}{l}\text { Open heart surgery } \\
\text { pulmonary valve } \\
\text { replacement } \\
n=10^{\star \star} \\
n=0 \text { (baseline) } \\
n=1 \text { ( } 3 \text { months) } \\
n=2 \text { (1 year) }\end{array}$ & Change & $P$ values \\
\hline \multicolumn{7}{|l|}{ 1. Anxiety/depression } \\
\hline Baseline & $53.86 \pm 5.35$ & & & $52.90 \pm 3.84$ & & \\
\hline 3 months postoperatively & $54.25 \pm 6.17$ & -0.23 & 0.853 & $50.78 \pm 1.99$ & -2.01 & 0.151 \\
\hline 1 year postoperatively & $52.36 \pm 5.07$ & -1.01 & 0.433 & $51.25 \pm 2.19$ & -1.91 & 0.190 \\
\hline \multicolumn{7}{|l|}{ 2. Withdrawal } \\
\hline Baseline & $55.64 \pm 5.85$ & & & $53.50 \pm 6.02$ & & \\
\hline 3 months postoperatively & $54.25 \pm 6.52$ & -1.05 & 0.310 & $52.78 \pm 5.21$ & -0.62 & 0.589 \\
\hline 1 year postoperatively & $51.91 \pm 4.53$ & -1.80 & 0.092 & $52.25 \pm 5.57$ & -1.48 & 0.218 \\
\hline \multicolumn{7}{|l|}{ 3. Social complaints } \\
\hline Baseline & $54.71 \pm 5.92$ & & & $53.80 \pm 4.32$ & & \\
\hline 3 months postoperatively & $53.48 \pm 6.36$ & -1.01 & 0.451 & $50.44 \pm 0.53$ & -2.43 & 0.108 \\
\hline 1 year postoperatively & $52.00 \pm 3.40$ & -2.09 & 0.131 & $52.38 \pm 4.84$ & -1.62 & 0.304 \\
\hline \multicolumn{7}{|l|}{ 4. Thought problems } \\
\hline Baseline & $56.07 \pm 6.96$ & & & $52.30 \pm 3.50$ & & \\
\hline 3 months postoperatively & $56.33 \pm 10.59$ & -0.98 & 0.565 & $52.22 \pm 4.02$ & -0.17 & 0.929 \\
\hline 1 year postoperatively & $50.45 \pm 1.21$ & -4.42 & 0.015 & $53.00 \pm 8.08$ & 0.64 & 0.750 \\
\hline \multicolumn{7}{|l|}{ 5. Attention problems } \\
\hline Baseline & $55.21 \pm 6.96$ & & & $53.20 \pm 5.53$ & & \\
\hline 3 months postoperatively & $52.92 \pm 5.25$ & -2.49 & 0.016 & $52.11 \pm 5.60$ & -0.49 & 0.673 \\
\hline 1 year postoperatively & $51.91 \pm 4.39$ & -2.89 & 0.007 & $52.38 \pm 4.41$ & -1.36 & 0.261 \\
\hline \multicolumn{7}{|l|}{ 6. Intrusive behaviour } \\
\hline Baseline & $53.71 \pm 4.18$ & & & $51.70 \pm 2.26$ & & \\
\hline 3 months postoperatively & $55.42 \pm 7.73$ & 1.29 & 0.291 & $51.33 \pm 2.35$ & -0.26 & 0.850 \\
\hline 1 year postoperatively & $51.27 \pm 2.24$ & -2.15 & 0.087 & $50.75 \pm 1.39$ & -0.85 & 0.553 \\
\hline \multicolumn{7}{|l|}{ 7. Aggressive behaviour } \\
\hline Baseline & $52.43 \pm 3.46$ & & & $52.10 \pm 3.51$ & & \\
\hline 3 months postoperatively & $52.08 \pm 3.60$ & -0.22 & 0.772 & $51.22 \pm 2.05$ & -0.89 & 0.291 \\
\hline 1 year postoperatively & $50.45 \pm 0.69$ & -1.06 & 0.171 & $50.25 \pm 0.46$ & -0.59 & 0.069 \\
\hline \multicolumn{7}{|l|}{ 8. Delinquent behaviour } \\
\hline Baseline & $52.14 \pm 3.18$ & & & $52.30 \pm 5.40$ & & \\
\hline 3 months postoperatively & $53.25 \pm 8.66$ & -0.60 & 0.470 & $51.89 \pm 4.28$ & -0.47 & 0.613 \\
\hline 1 year postoperatively & $50.18 \pm 0.40$ & -1.48 & 0.084 & $50.25 \pm 0.71$ & -0.88 & 0.357 \\
\hline
\end{tabular}

Subscale changes are presented as mean $\pm \mathrm{SD}$. T-score changes from baseline to 3 months and 1 year are presented in descriptive statistics. Negative numbers postoperatively indicated improvement from baseline within each group.

${ }^{* *}$ Numbers of patients were less in each treatment group because only children aged $>11$ years were included.

$\mathrm{n}$ (baseline), $\mathrm{n}(3$ months) and $\mathrm{n}$ (1 year) are given for missing data at different time points.

${ }^{*} \mathrm{P}$ value and changes were analysed using a linear-effects model.

Bold numbers are statistical significant changes.

at 1 year concerning the right ventriculo-arterial gradient and the NYHA class. A difference in patient-reported outcomes was found between the groups, a significant improvement in psychosocial endpoints was observed within the PPVI group at 3 months concerning Thought problems, and in subscale Attention problems at 3 months and 1 year after treatment. No such finding was observed either at 3 months or 1 year after treatment in the open surgery group. A significant association was also found between the right ventricle to pulmonary artery 
gradient pressure and psychosocial function with respect to the Anxiety/Depression subscale at 3 months postoperatively in the PPVI group. Psychosocial function in patients with congenital heart disease may be attributed to numerous factors such as age, genetics and altered cerebral perfusion in utero. ${ }^{15}$ Open heart surgery with extracorporeal circulation may add to these factors in challenging psychosocial function. This may explain why the patients treated by the percutaneous catheter technique experienced an improvement in psychosocial function, not seen in the surgical patients. ${ }^{16}$ In a previous paper from the present study covering the economic effects of the herein-described treatment methods, we demonstrated that the mean length of hospital stay in the open surgery group was significantly longer than in the PPVI group. ${ }^{23}$ This may have also affected the patients' reported experience.

Adults with complex congenital heart disease have an increased risk of cumulative challenges associated with significant morbidity and an increased risk of mortality when they reach the age of 50 years. ${ }^{27}$ These patients have an increased risk of anxiety, depression and social cognition issues, resulting in challenges in educational attainment, employment and social and emotional issues. ${ }^{16}$

Surgery is a more comprehensive treatment than the percutaneous technique and therefore has higher physical and psychological risks. Dos et $a l^{13}$ described arrhythmias, respiratory complications and renal dysfunction as the most common early postoperative events following surgery in older patients with multiple sternotomies at highest risk for prolonged hospitalisation. ${ }^{13}$ Interventional techniques are evolving, and more patients are likely to be treated percutaneously in the future. This may impact long-term quality of life in these patients.

We previously reported positive patient experiences following PPVI. A short hospital stay, easy rehabilitation and rapid life normalisation were common positive experiences. ${ }^{11}$ The patients may have adapted and changed expectations accordingly. A near-normal life expectancy ${ }^{28}$ in later life may also become a challenging issue for these patients.

The self-reported NYHA classification of heart failure sustained significant at 1 year only in the PPVI group, indicating less symptoms and a rehabilitation in favour of the percutaneously treated patients.

The self-reported NYHA classification is not necessarily only related to the initial diagnosis but can also be related to the assessment of perceived health. ${ }^{29}$ A significant correlation among heart function, the degree of pulmonary stenosis and psychosocial outcomes with respect to the Anxiety/Depression subscale was observed in favour of the percutaneous treatment at 3 months $(p=0.038)$. This finding may indicate that the reduction in the right ventricle to pulmonary artery gradient pressure was a result of reductions in anxiety and depression after treatment.

This was not a randomised study, and the groups differed with respect to type of pulmonary valve lesion.
Patients with predominantly valve stenosis were offered PPVI, while most patients in the surgery group had pulmonary regurgitation caused by mixed underlying diseases. Therefore, we cannot rule out the possibility that differences in diseases may have impacted the psychosocial outcomes.

\section{CONCLUSION}

Both methods led to significant clinical improvement. A significant reduction in thought and attention problems such as intrusive behaviour was observed in patients who underwent the percutaneous procedure. After adjusting for the right ventricle to pulmonary artery gradient pressure, the attention problems significantly decreased in the PPVI group. A significant improvement in the NYHA functional score was observed in both groups. Complications such as reintervention, bleeding and arrhythmia were only observed in the open heart surgery group.

\section{Strengths and limitations of the study}

This was a prospective study with follow-up data. Self-reporting contributes to a more comprehensive assessment, which is an advantage over the established objective measures of illness severity. We used a well-established and validated instrument to measure psychosocial function and self-reported data. Increasingly more studies are showing that the NYHA functional class is a complementary classification to the level of disease severity because it involves the self-reporting of symptoms defined by the patient. ${ }^{29}$ Our findings should be interpreted cautiously. The most important limitation is the small sample size and missing data, which could have increased the probability of type 2 errors. Our study population, which mainly comprised teenagers, was probably influenced by the amount of missing data. This vulnerable patient population is asked to participate in considerable ongoing research, probably influencing the willingness to communicate or share experiences. Our population also exhibited large age differences. The instrument used to assess psychosocial function included only children aged $>11$ years, resulting in a response rate of $63 \%$ for the ASEBA scores.

Acknowledgements We thank all, in particular, the patients who participated in this study. The authors thank Angela Morben, DVM, ELS, from Edanz Group (www. edanzediting.com/ac) for editing a draft of this manuscript.

Contributors BA, GD, HL, EF and MHA were responsible for the study design. BA and GD collected the data. BA, LMD and MHA analysed the data. All authors revised the work critically, read and approved the final manuscript, and agree to be accountable for all aspects of the work.

Funding The South Eastern Norway Regional Health Authority funded this study (grant no. 2011020).

Competing interests None declared.

Patient consent Obtained.

Ethics approval Regional ethical committee of South East, Norway.

Provenance and peer review Not commissioned; externally peer reviewed.

Data sharing statement No additional data are available.

Open access This is an open access article distributed in accordance with the Creative Commons Attribution Non Commercial (CC BY-NC 4.0) license, which 
permits others to distribute, remix, adapt, build upon this work non-commercially, and license their derivative works on different terms, provided the original work is properly cited and the use is non-commercial. See: http://creativecommons.org/ licenses/by-nc/4.0/

(c) Article author(s) (or their employer(s) unless otherwise stated in the text of the article) 2018. All rights reserved. No commercial use is permitted unless otherwise expressly granted.

\section{REFERENCES}

1. Eicken A, Ewert $P$, Hager A, et al. Percutaneous pulmonary valve implantation: two-centre experience with more than 100 patients. Eur Heart J 2011;32:1260-5.

2. McElhinney DB, Hellenbrand WE, Zahn EM, et al. Short- and medium-term outcomes after transcatheter pulmonary valve placement in the expanded multicenter US melody valve trial. Circulation 2010;122:507-16.

3. Lurz P, Coats L, Khambadkone S, et al. Percutaneous pulmonary valve implantation: impact of evolving technology and learning curve on clinical outcome. Circulation 2008;117:1964-72.

4. Butera G, Milanesi O, Spadoni I, et al. Melody transcatheter pulmonary valve implantation. Results from the registry of the Italian Society of Pediatric Cardiology. Catheter Cardiovasc Interv 2013;81:310-6.

5. Fraisse A, Aldebert P, Malekzadeh-Milani S, et al. Melody® transcatheter pulmonary valve implantation: results from a French registry. Arch Cardiovasc Dis 2014;107:607-14.

6. Cools B, Brown SC, Heying R, et al. Percutaneous pulmonary valve implantation for free pulmonary regurgitation following conduitfree surgery of the right ventricular outflow tract. Int $J$ Cardiol 2015;186:129-35.

7. Nordmeyer J, Khambadkone S, Coats L, et al. Risk stratification, systematic classification, and anticipatory management strategies for stent fracture after percutaneous pulmonary valve implantation. Circulation 2007;115:1392-7.

8. Ringewald JM. Recent advances in transcatheter pulmonary valve delivery. Curr Opin Cardiol 2016;31:88-94.

9. Lurz P, Nordmeyer J, Giardini A, et al. Early versus late functional outcome after successful percutaneous pulmonary valve implantation: are the acute effects of altered right ventricular loading all we can expect? J Am Coll Cardiol 2011;57:724-31.

10. Fiszer R, Dryżek P, Szkutnik M, et al. Immediate and long-term outcomes of percutaneous transcatheter pulmonary valve implantation. Cardiol J 2017;24:604-11.

11. Andresen $\mathrm{B}$, Andersen $\mathrm{MH}$, Lindberg $\mathrm{H}$, et al. Perceived health after percutaneous pulmonary valve implantation: in-depth interviews of patients and next-of-kin. BMJ Open 2014;4:e005102.

12. Hager A, Schubert $S$, Ewert $P$, et al. Five-year results from a prospective multicentre study of percutaneous pulmonary valve implantation demonstrate sustained removal of significant pulmonary regurgitation, improved right ventricular outflow tract obstruction and improved quality of life. Eurolntervention 2017;12:1715-23.
13. Dos L, Dadashev A, Tanous D, et al. Pulmonary valve replacement in repaired tetralogy of Fallot: determinants of early postoperative adverse outcomes. J Thorac Cardiovasc Surg 2009;138:553-9.

14. Shillingford AJ, Glanzman MM, Ittenbach RF, et al. Inattention, hyperactivity, and school performance in a population of schoolage children with complex congenital heart disease. Pediatrics 2008;121:e759-e767.

15. Sarrechia I, De Wolf D, Miatton M, et al. Neurodevelopment and behavior after transcatheter versus surgical closure of secundum type atrial septal defect. J Pediatr 2015;166:31-8.

16. Marelli A, Miller SP, Marino BS, et al. Brain in congenital heart disease across the lifespan: the cumulative burden of injury. Circulation 2016;133:1951-62.

17. Tabbutt S, Gaynor JW, Newburger JW. Neurodevelopmental outcomes after congenital heart surgery and strategies for improvement. Curr Opin Cardiol 2012;27:82-91.

18. Lerwick JL. Psychosocial implications of pediatric surgical hospitalization. Semin Pediatr Surg 2013;22:129-33.

19. Morton PD, Ishibashi N, Jonas RA. Neurodevelopmenta abnormalities and congenital heart disease: insights into altered brain maturation. Circ Res 2017;120:960-77.

20. Black N. Patient reported outcome measures could help transform healthcare. BMJ 2013;346:f167.

21. Baumgartner H, Bonhoeffer P, De Groot NM, et al. ESC Guidelines for the management of grown-up congenital heart disease (new version 2010). Eur Heart J 2010;31:2915-57.

22. Hijazi ZM, Ruiz CE, Zahn E, et al. SCAI/AATS/ACC/STS operator and institutional requirements for transcatheter valve repair and replacement, part III: pulmonic valve. Catheter Cardiovasc Interv 2015;86:85-93.

23. Andresen B, Mishra V, Lewandowska M, et al. In-hospital cost comparison between percutaneous pulmonary valve implantation and surgery. Eur J Cardiothorac Surg 2017;51:747-53.

24. Achenbach TM, Ruffle TM. The child behavior checklist and related forms for assessing behavioral/emotional problems and competencies. Pediatr Rev 2000;21:265-71.

25. Nøvik TS. Validity of the child behaviour checklist in a Norwegian sample. Eur Child Adolesc Psychiatry 1999;8:247-54.

26. Yancy CW, Jessup M, Bozkurt B, et al. ACC/AHA/HFSA Focused Update of the 2013 ACCF/AHA Guideline for the Management of Heart Failure: A Report of the American College of Cardiology/ American Heart Association Task Force on Clinical Practice Guidelines and the Heart Failure Society of America. Circulation 2017;2017:e137-e61.

27. Dennis M, Moore B, Kotchetkova I, et al. Adults with repaired tetralogy: low mortality but high morbidity up to middle age. Open Heart 2017;4:e000564.

28. Hunter AL, Swan L. Quality of life in adults living with congenital heart disease: beyond morbidity and mortality. J Thorac Dis 2016;8:E1632-E1636.

29. Moons P, Van Deyk K, De Geest S, et al. Is the severity of congenital heart disease associated with the quality of life and perceived health of adult patients? Heart 2005;91:1193-8. 